\title{
Reducción de la transmisión madre hijo del VIH en Colombia: dos años de experiencia nacional, 2003-2005
}

\author{
Ricardo García 1, Franklyn Prieto ${ }^{2}$, Carlos Arenas ${ }^{2}$, Julio Rincón ${ }^{3}$, Sidia Caicedo ${ }^{2}$, Gloria Rey ${ }^{4}$ \\ 1 Onusida-Colombia, Bogotá, D.C., Colombia. \\ 2 Proyecto Madre Hijo, Colombia, Bogotá, D.C., Colombia. \\ ${ }^{3}$ Federación de Cooperativas de Hospitales de Colombia, Feredsalud, Bogotá, D.C., Colombia. \\ ${ }^{4}$ Instituto Nacional de Salud, Bogotá, D.C., Colombia.
}

Introducción. Desde el 2003, en Colombia se desarrolla el Proyecto Nacional de Reducción de la Transmisión Madre Hijo de VIH, cuyo objetivo es prevenir la transmisión vertical de $\mathrm{VIH}$ mediante la incorporación de la prueba voluntaria de VIH durante el control prenatal, el tratamiento y la profilaxis antirretroviral en la gestante infectada y el niño expuesto, el parto por cesárea y la sustitución de la leche materna.

Objetivo. Describir los resultados de la implementación de la estrategia de prevención de la transmisión madre hijo 2003-2005.

Materiales y métodos. Se hizo el estudio descriptivo de la cobertura alcanzada, la probabilidad de transmisión vertical y los factores asociados y prevalencias registradas en cada departamento. Se exploró la probabilidad de transmisión según tratamiento y se identificaron las diferencias por regiones.

Resultados. El proyecto se implementó en 757 municipios (68\%), en los cuales se realizó la prueba de VIH a 200.853 gestantes, y se detectaron 377 infectadas $(0,19 \%)$, con mayor seropositividad en la región Caribe, en Quindío y en Santander. Se completó el seguimiento a 285 mujeres y sus hijos, y se registraron 12 casos en niños. La probabilidad de transmisión con el suministro oportuno del protocolo $(n=170)$ fue de $1,78 \%$ (IC95\%: 0,37 a 5,13\%). Los factores relacionados con la transmisión fueron: carga viral inicial mayor de $10.000 / \mathrm{mm}^{3}$, ausencia de control prenatal y captación tardía en el embarazo. No se encontraron diferencias estadísticas entre los esquemas antirretrovirales utilizados. La región Caribe tuvo menor cobertura del control prenatal y mayor captación tardía.

Conclusiones. La reducción de la transmisión madre hijo de VIH es una intervención preventiva eficaz que favorece el fortalecimiento de los servicios de control prenatal. El sostenimiento de la estrategia con cobertura nacional debe ser una meta de los gobiernos nacional y regionales y de las entidades aseguradoras.

Palabras clave: virus de inmunodeficiencia humana, transmisión vertical de enfermedad, prevención y control, atención prenatal, diagnóstico prenatal, terapia antirretroviral altamente activa.

Reduction of VIH mother-to-child transmission in Colombia, two years of experience, 20032005

Introduction. A national initiative on reduction of HIV mother-to-child-transmission is being implemented since 2003 in Colombia, including HIV counseled and voluntary testing as part of the routine antenatal care, comprehensive care with ARV treatment to HIV-positive pregnant women and their infected children, caesarian delivery, and replacement of breast milk.

Objective. To describe the achievements in the implementation of the prevention strategy of mother-to-child HIV transmission, 2003-2005.

Materials and methods. The implementation procedures of the Project are described, as well as the coverage percentages achieved, the prevention of vertical transmission and its associated factors, and the six-month prevalence by geographical departments. The probability of transmission adjusted to the ARV treatment offered and the differences by regions are also analyzed. 
Results. The Project was implemented in 757 municipalities $(68 \%)$; diagnostic tests were performed to 200.853 pregnant women, 377 of whom were diagnosed as HIV positive $(0.19 \%)$, with higher prevalences in the Caribbean region, and in the Departments of Quindio and Santander. Complete six-month follow-up after delivery was provided to 285 women and their neonates (12 of whom were VIH-positive). The probability of transmission with the use of ARV schemes during pregnancy $(n=170)$ was $1.78 \%$ (IC95\%: 0,37-5,13\%). Factors related to probability of transmission were: initial viral load $>10.000 / \mathrm{mm}^{3}$, absence of antenatal care, and late recruitment of pregnant women. No statistical differences were found between the ARV schemes used. In the Caribbean region, antenatal care was lower, and late recruitment of pregnant women was higher.

Conclusions. Reduction of HIV mother-to-child-transmission is an effective preventive intervention, which also strengthens the quality of antenatal care services. Sustainability of this initiative, with nationwide coverage, must be a target for national and regional public health authorities, and for health care providers.

Key words: human immunodeficiency virus-HIV, disease transmission, vertical/prevention and control, prenatal care, prenatal diagnosis, highly active antiretroviral therapy.

La epidemia del $\mathrm{VIH} /$ sida presenta un progresivo crecimiento entre las mujeres, como resultado de su mayor vulnerabilidad ante las desigualdades de sexo predominantes en muchas sociedades (1-4). En el mundo, la proporción de mujeres con VIH o sida ha aumentado: en 1997, 41\% de los casos reportados correspondía a mujeres; al final de 2004 , cerca de $50 \%$ de las personas con VIH o sida en el mundo estaba conformado por mujeres (5). Esta tendencia es más evidente en África y en el Caribe, donde la transmisión heterosexual predomina desde el inicio de la epidemia. Actualmente, en los países del África subsahariana, la prevalencia de infección en mujeres menores de 25 años es dos a tres veces mayor que en hombres de la misma edad; $57 \%$ de los adultos infectados y $75 \%$ de los casos reportados en menores de 25 años corresponde a mujeres $(1,4)$.

En Colombia, la "feminización" de la epidemia está ocurriendo gradualmente, y en algunas regiones esta realidad es evidente desde hace varios años. Se observa un progresivo cambio del patrón de transmisión homosexual hacia la transmisión por coito heterosexual, particularmente en la región Caribe, donde, desde comienzos de los noventa,

\author{
Correspondencia: \\ Ricardo García, Carrera 22 No. 86-14, oficina 601, Bogotá, \\ D.C., Colombia. \\ PBX: 57-1-6164676 \\ proyectomadrehijo@yahoo.com
}

Recibido: 21/07/05; aceptado: 17/11/05 las nuevas infecciones en mujeres jóvenes aumentaron más que en los hombres de la misma edad $(6,7)$. La prevalencia nacional de infección en la población general de 15 a 49 años se estima entre $0,64 \%$ y $0,7 \%$, lo cual indicaría que actualmente están infectadas alrededor de 58.000 mujeres en edad fértil.

El creciente número de infecciones en mujeres en edad fértil implica un progresivo aumento de los casos de sida pediátrico. El primer caso de transmisión madre-hijo en Colombia se informó en 1987, y hasta diciembre de 2003 se habían notificado 798 casos de transmisión perinatal, con un aumento sostenido desde 1995. Al final de 2004 se estimaba que, en Colombia, había entre 4.000 y 8.000 niños infectados con el VIH (8). Si un millón de mujeres estuvieran embarazadas, 6.900 podrían estar infectadas con $\mathrm{VIH}$; con una probabilidad de transmisión madre-hijo de $\mathrm{VIH}$ de $30 \%$ a $40 \%$ (9), y sin aplicación de las medidas de prevención, se tendrían entre 2.070 y 2.760 infecciones neonatales anuales nuevas.

La transmisión madre hijo del VIH ocurre durante el embarazo (prenatal), en el momento del parto (intraparto) o a través de la leche materna (posparto). La transmisión prenatal ocurre entre $30 \%$ y $35 \%$ de los casos, la transmisión intraparto entre $55 \%$ y $65 \%$ y la lactancia materna aporta el $15 \%$ a $20 \%$ restante (9). Desde la publicación de los resultados del protocolo PACTG 076 (Pediatric AIDS Clinical Trials Group) (10), diversos estudios evidenciaron la eficacia de la terapia antirretroviral 
para reducir la transmisión de VIH madre-hijo. Inicialmente se recomendó la terapia con zidovudina (ZDV) como protocolo de elección (1114). Posteriormente, los diferentes esquemas con dos medicamentos tuvieron mayor eficacia que los esquemas con un solo medicamento (15-17). Actualmente, el uso de la terapia triple es el más recomendado (18-19). Sin embargo, la selección de los esquemas depende en gran parte de los recursos financieros disponibles, por lo que existe una amplia gama de esquemas de tratamiento utilizados en los diferentes países (20). Con los esquemas utilizados han sido notorios los logros en la reducción de la transmisión de VIH madrehijo, pero son pocos los países que han desarrollado y sostenido estrategias de cobertura nacional que desemboquen en la reducción de la incidencia de infección perinatal (21).

En Colombia, el Sistema General de Seguridad Social en Salud no ha logrado el nivel de cobertura universal después de su implementación en 1994 $(22,23)$. Actualmente, la cobertura del sistema de salud alcanza $66 \%$ del total de la población, y no se prevé un aumento significativo de esta cobertura debido a las restricciones y dificultades financieras que afronta el Estado colombiano (24). De acuerdo con la información oficial, $34 \%$ de las mujeres en edad fértil no tiene acceso al sistema de aseguramiento y su atención en salud depende del subsidio a la oferta.

Las actividades de atención y control prenatal en las regiones y departamentos siguen las guías del programa nacional implementado desde inicios de los ochenta $(25,26)$. La cobertura estimada de los servicios de atención y control prenatal es de $89 \%$ en áreas urbanas y de $71 \%$ en áreas rurales (27). Aunque las entidades aseguradoras de salud comparten la responsabilidad de estas acciones, el sector público mantiene estos programas enfocados al segmento de la población más pobre.

El Proyecto Nacional para la Reducción de la Transmisión Madre Hijo, coordinado por una alianza interinstitucional conformada por el Programa Conjunto de las Naciones Unidas sobre el VIH/SIDA (ONUSIDA), el Instituto Nacional de Salud (INS) y la Federación Colombiana de
Cooperativas de Hospitales (FEREDSALUD), se gestó a partir de la experiencia de siete iniciativas regionales apoyadas por Onusida desde 1999, en cuyo curso se realizaron 16.000 pruebas diagnósticas a mujeres embarazadas (GarcíaBernal R, Vargas LS. Regional pilot programs for reduction of vertical transmission of HIV in Colombia. Proceedings of the I Fórum e II Conferencia de Cooperacao Técnica Horizontal da America Latina e do Caribe em HIV/AIDS e DST; 2000 Nov 6-11. Rio de Janeiro, Brazil). Con base en estas experiencias, en abril de 2003 se iniciaron las actividades a nivel nacional.

Los objetivos de esta iniciativa son: 1) promover el reconocimiento y la conciencia entre las mujeres colombianas en edad reproductiva de la importancia de conocer su estado serológico para la infección por VIH; 2) ofrecer pruebas diagnósticas para VIH en forma gratuita y oportuna como parte de la atención prenatal de todas las mujeres embarazadas, particularmente aquéllas no afiliadas al sistema de salud; 3) proveer atención integral en salud a las mujeres embarazadas infectadas con $\mathrm{VIH}$, incluido el tratamiento antirretroviral; 4) brindar apoyo psicosocial a las mujeres diagnosticadas y a sus familias; 5) promover y lograr el compromiso y participación de las entidades aseguradoras del sistema de salud, y 6) promover e implementar una política específica de salud pública dirigida a mantener en el nivel mínimo el riesgo de transmisión vertical del VIH en Colombia.

\section{Procedimientos generales}

El proyecto inició su implementación mediante la capacitación de los equipos departamentales y municipales de salud y la definición de los mecanismos administrativos y asistenciales necesarios. Las sesiones de entrenamiento incluyeron aspectos epidemiológicos, clínicos y psicosociales relacionados con la vulnerabilidad de la mujer ante el VIH/sida y con la transmisión madre hijo, con énfasis en la asesoría pre y post prueba y en los modelos de intervención para la provisión de apoyo psicosocial a las mujeres infectadas con VIH y a sus familiares. Se llevaron a cabo 54 talleres de capacitación de 8 horas de duración, con la participación de aproximadamente 
3.500 profesionales del sector de la salud. En 31 departamentos se realizaron actividades de abogacía y se concertó con los gobernadores y alcaldes. Se suscribieron 20 convenios de cooperación entre el proyecto y los gobiernos departamentales. Para informar a la población de la existencia del proyecto se diseñó una campaña publicitaria cuyo lema fue "a tu hijo transmítele sólo amor", con comerciales de radio y televisión que tuvieron emisión nacional, regional y local durante periodos bimensuales o trimestrales no consecutivos.

Las beneficiarias del proyecto fueron gestantes sin afiliación al sistema de salud (vinculadas), quienes fueron captadas en los servicios de salud de las instituciones públicas de prestación de servicios de salud, y a quienes se les brindó asesoría y consejería en VIH y se les ofreció acceso inmediato a la prueba presuntiva, tomándoseles la muestra de sangre a quienes aceptaran, previo consentimiento informado. Durante la gestación, a los tres meses, se tomó una segunda muestra a las gestantes con pareja infectada, con múltiples compañeros sexuales en los últimos 6 meses, o con punto de corte alto en la primera muestra sometida a la prueba ELISA.

Para la realización de la prueba diagnóstica presuntiva se recolectaron muestras de $5 \mathrm{ml}$ de sangre en tubo separador de suero SSTM, usando las precauciones universales para el manejo de fluidos (28), separando el suero y seleccionando muestras sin hemólisis. El suero fue almacenado a 2 a $8^{\circ} \mathrm{C}$ por periodos de 2 a 3 días y enviado a los laboratorios departamentales de acuerdo con las regulaciones internacionales de transporte de muestras para diagnóstico $(29,30)$.

La presencia de anticuerpos anti-VIH 1-2 fue detectada mediante la técnica ultramicroelisa de Tecnosuma ${ }^{\circledR}$ (31) en los laboratorios departamentales de salud pública. Las muestras con niveles de absorbancia igual o mayor al valor límite se consideraron reactivas y se procesó una nueva muestra para una segunda prueba ELISA. La prueba de Western blot (Murex HIV 1de Abbott (B) se utilizó como confirmatoria para las muestras reactivas en las dos pruebas de ELISA. Los resultados se interpretaron como negativo, positivo o indeterminado según las pautas recomendadas por los CDC de Atlanta (32) y ASTPHLD (33).

Las pruebas confirmatorias se realizaron en los Laboratorios de Salud Pública de Atlántico, Antioquia y Valle del Cauca, en el Laboratorio Nacional de Referencia de Virología del Instituto Nacional de Salud en Bogotá y en el Centro de Análisis Molecular de Bogotá, dependiendo del origen geográfico de la prueba ELISA reactiva.

Las gestantes que fueron detectadas como negativas, recibieron asesoría y consejería después de la prueba. Aquéllas detectadas como positivas o indeterminadas ingresaron al protocolo de prevención. A las gestantes con resultado indeterminado se les inició manejo farmacológico como conducta profiláctica, ante la posibilidad de que el resultado correspondiera al periodo de ventana inmunológica (34-36).

\section{Protocolo de atención y tratamiento antirretroviral}

Al inicio del proyecto se ofrecieron como opciones de tratamiento antirretroviral a la gestante los siguientes: desde la semana 14, $300 \mathrm{mg}$, por vía oral (VO) de zidovudina (ZDV) dos veces al día; desde la semana 32, $300 \mathrm{mg}$ de ZDV más 150 $\mathrm{mg}, \mathrm{VO}$, de lamivudina (3TC) dos veces al día (16); durante el trabajo de parto y el parto se administró el esquema de $2 \mathrm{mg} / \mathrm{kg}$ de ZDV, intravenoso (IV) (16) y al recién nacido se le suministró ZDV más 3TC durante seis semanas $(15,37)$; en el caso de niños prematuros, las dosis fueron ajustadas de acuerdo a la edad de la gestación al nacer, y la vía de aplicación se escogió de acuerdo con la tolerancia frente a la vía oral (38). En caso de detección al final del embarazo, la opción utilizada fue ZDV, IV, más $200 \mathrm{mg}$, VO, de nevirapina (NVP) en dosis única para la gestante al inicio del trabajo de parto $(39,40)$. Desde octubre de 2004, las combinaciones utilizadas fueron ZDV + 3TC + NVP o ZDV + 3TC + nelfinavir (NFV) $(41,42)$; la decisión sobre el tratamiento dependió principalmente de la edad de gestación al momento de la captación, la carga viral y el criterio del equipo médico tratante (43-44).

Los esquemas de tratamiento suministrados y su dosificación se presentan en los cuadros 1 y 2 . 
En la mayoría de los casos, el manejo y seguimiento clínico de la mujer embarazada y del recién nacido lo hicieron médicos generales con entrenamiento y pediatras y ginecoobstetras de los hospitales públicos de segundo y tercer nivel de cada departamento, a donde eran remitidas las pacientes para la atención del parto por cesárea. En las 25 capitales departamentales donde se presentaron los casos, médicos internistas, infectólogos, ginecoobstetras y pediatras participaron en el seguimiento clínico de las mujeres gestantes diagnosticadas y de sus hijos expuestos.

A las gestantes diagnosticadas se les evaluó la carga viral plasmática y el recuento de linfocitos CD4/CD8 en el momento de la confirmación diagnóstica (Western blot) y en el último mes de embarazo (semana 32 a 34).Para el diagnóstico de infección en el niño, se evaluó la carga viral al mes y a los 4 a 5 meses, en esta última ocasión acompañada de un recuento de linfocitos (45-47).

La carga viral se evaluó mediante b-DNA (Versant HIV-1 RNA 3.0 de Bayer Corporation®) o RNAPCR (Amplicor HIV-1 Monitor de Roche $\AA^{\circledR}$ ) ultrasensible. El recuento de linfocitos CD4/CD8 se realizó mediante citometría de flujo siguiendo el método FACScan de Becton Dickinson® y utilizando los datos de referencia internacionales para individuos infectados con VIH (48). Estas pruebas fueron realizadas por laboratorios de Cali (Cideim), Medellín (Laboratorio Clínico Santa María) y Bogotá, D.C. (Centro de Análisis Molecular).

En los controles clínicos de la gestante se valoró la adherencia al tratamiento, los efectos adversos,

Cuadro 1. Esquemas de tratamiento y profilaxis antirretroviral utilizados en el Proyecto Nacional de Reducción de la Transmisión Madre Hijo del VIH.

\begin{tabular}{lcccc}
\hline Esquema & \multicolumn{2}{c}{ Prenatal } & Intraparto & Posparto \\
\cline { 2 - 4 } & $\mathbf{1 4}$ a $\mathbf{3 2}$ semanas $^{*}$ & $\mathbf{3 2}$ a $\mathbf{4 0 ~ s e m a n a s ~}$ & & \\
\hline Esquema 1 & ZDV & ZDV + 3TC & ZDV & ZDV + 3TC \\
Esquema 2 & & ZDV + 3TC & ZDV & ZDV + 3TC \\
Esquema 3 & & & ZDV & ZDV + 3TC \\
Esquema 5 & & & ZDV & ZDV + 3TC + NFV \\
Esquema 6 & ZDV + 3TC + NVP & NVP + ZDV & ZDV + 3TC \\
\hline
\end{tabular}

* Desde el momento de la captación

ZDV: zidovudina; 3TC: lamivudina; NFV: nelfinavir; NVP: nevirapina

Cuadro 2. Dosificación de los antirretrovirales utilizados en el Proyecto Nacional de Reducción de la Transmisión Madre Hijo del VIH.

\begin{tabular}{llccc}
\hline Medicamento* $^{*}$ & Momento & Vía & Cantidad & Dosificación \\
\hline ZDV & Embarazo & VO & $300 \mathrm{mg}$ & $\mathrm{c} / 12$ horas \\
3TC & Embarazo & VO & $150 \mathrm{mg}$ & $\mathrm{c} / 12$ horas \\
NFV & Embarazo & VO & $750 \mathrm{mg}$ & $\mathrm{c} / 8$ horas \\
NVP & Embarazo & VO & $200 \mathrm{mg}$ & $\mathrm{c} / 12$ horas \\
ZDV & Preparto & N & $1-2 \mathrm{mg} / \mathrm{kg}$ & $\mathrm{c} / 3$ horas \\
NVP & Preparto & VO & $200 \mathrm{mg}$ & dosis única \\
ZDV & Recién nacido* & VO & $2 \mathrm{mg} / \mathrm{kg}$ & $\mathrm{c} / 6$ horas \\
3TC & Recién nacido** $^{* *}$ & VO & $4 \mathrm{mg} / \mathrm{kg}$ & c/24 horas \\
\hline
\end{tabular}

* Ver cuadro 1.

** Ajustada de acuerdo a edad de la gestación al nacer (Capurro).

VO: vía oral; IV: intravenosa . 
signos y los síntomas relacionados con sida y enfermedades oportunistas, carga viral y recuento de linfocitos.

La vía de atención del parto recomendada fue la cesárea, teniendo en cuenta la menor probabilidad de transmisión del VIH intraparto (49-53), particularmente cuando no se podía garantizar una carga viral indetectable previa al trabajo de parto. Se administró zidovudina intravenosa por lo menos durante 3 horas antes de la cesárea. Se recomendó a todas las puérperas alimentar a sus hijos con fórmula láctea de manera exclusiva durante los primeros seis meses de vida $(54,55)$. La fórmula láctea de reemplazo fue suministrada por el proyecto durante un periodo de seis meses. Las mujeres en puerperio recibieron asesoría en nutrición infantil y planificación familiar. En las consultas de control y seguimiento a los infantes se estableció el estado de crecimiento y desarrollo, el suministro de la fórmula láctea, el esquema de vacunación recibido y el estado general de salud.

\section{Manejo y procesamiento de la información recolectada}

Los formatos de recolección de información diligenciados durante los procesos de captación, asesoría y realización de las pruebas, fueron almacenados en las ciudades capitales sedes de coordinación regional, garantizando la confidencialidad. La información, recolectada en formularios, se incorporó en una base de datos Access ${ }^{\circledR}$. Los formatos correspondientes a mujeres diagnosticadas con la infección por VIH fueron enviados a la sede de la coordinación nacional en Bogotá.

La información registrada de las mujeres gestantes diagnosticadas con la infección por VIH incluyó fecha de diagnóstico, municipio de residencia, edad, estado civil, ocupación, semana de gestación en el momento de la captación, semana de gestación al inicio del tratamiento, esquema de tratamiento antirretroviral recibido, resultado de la primera y segunda cargas virales, fechas de realización de las pruebas, tipo de parto, acceso a la seguridad social y continuidad del tratamiento antirretroviral suministrado por las entidades aseguradoras o por los gobiernos departamentales y municipales. Del recién nacido expuesto se registró la edad de gestación al momento del parto, el peso al nacer y Apgar a los 5 minutos para la monitorización de posibles efectos adversos in utero (56), así como el esquema de profilaxis administrado y el resultado de la carga viral al mes y a los seis meses.

\section{Monitorización, evaluación y control de calidad}

Las acciones de seguimiento, verificación y asistencia técnica se basaron en visitas periódicas del equipo de coordinación nacional y de los coordinadores regionales a los sitios de ejecución de las actividades de captación, tamizaje y seguimiento de las mujeres diagnosticadas. Se efectuaron dos actividades de evaluación del proceso y de los resultados obtenidos, la primera en julio de 2004 y la segunda en abril de 2005. El control de calidad de las pruebas diagnósticas y demás procedimientos de laboratorio fue realizado en el Laboratorio Nacional de Referencia de Virología del Instituto Nacional de Salud.

\section{Plan de análisis}

Inicialmente se analizó la información disponible sobre la cobertura del proyecto y sobre los procesos desarrollados para su implementación. Las variables seleccionadas para el análisis fueron: número de mujeres captadas en los servicios de control prenatal, número y porcentaje de pruebas realizadas por departamento y número de casos de infección con VIH en gestantes. Se estableció la correlación entre el número de gestantes tamizadas y el número de gestantes detectadas como positivas, utilizando un modelo de regresión lineal, y calculando el coeficiente de correlación y su intervalo de confianza de $95 \%$. También se identificó la relación entre el incremento del número de pruebas realizadas y los diferentes hitos del proyecto como los procesos de capacitación, el número de departamentos en el proyecto y la emisión de los mensajes de televisión y radio.

Como aproximación a la prevalencia departamental, se tomaron periodos de 6 meses, entre julio y diciembre de 2003 y de 2004. Para cada prevalencia se estableció un intervalo de confianza de $95 \%$. Los resultados en la prevención de la transmisión de VIH madre hijo se evaluaron a partir de la cohorte de gestantes 
diagnosticadas como infectadas y de sus hijos expuestos, que fueron seguidas hasta el sexto mes después del parto.

Para los casos de infección con $\mathrm{VIH}$ en gestantes se seleccionaron las siguientes variables para el análisis de la situación nacional y la comparación por regiones: edad, estado civil, ocupación, edad de la gestación al momento de la captación, antecedente de control prenatal, afiliación posparto al sistema de salud y acceso al tratamiento posterior a su vinculación con el Proyecto. Para los hijos e hijas se analizó el peso al nacer, el Apgar a los 5 minutos y la edad de gestación (Capurro).

Se realizó la comparación de los resultados por regiones. Las regiones geo-políticas fueron tomadas de la clasificación nacional del Consejo Regional de Política Social y Económica (Corpes) (57). Se determinaron las diferencias entre los hallazgos de las dos actividades de evaluación efectuadas a nivel nacional durante los meses de junio de 2004 y marzo de 2005. Se calcularon diferencias de proporciones, sus respectivos intervalos de confianza de $95 \%$ y la prueba de hipótesis utilizando ji al cuadrado, con una significación de $5 \%$.

La probabilidad de transmisión se estimó como el número de niños infectados al término de seis meses de seguimiento después del parto entre el número de niños expuestos al VIH con seis meses de seguimiento. Se consideró infectado con VIH todo niño con una carga viral PCR-RNA mayor de 1.000 copias $/ \mathrm{mm}^{3}$ durante los 6 meses de seguimiento, determinada al mes 0 a los seis meses $(58,59)$.

Se exploró la probabilidad de la transmisión madre hijo según el esquema de tratamiento antirretroviral recibido por la gestante, determinando las diferencias significativas mediante pruebas de hipótesis con validación estadística por medio de la prueba de ji al cuadrado, y asumiendo diferencias con un valor de $p$ menor de 0,05.

La probabilidad de la transmisión madre hijo se relacionó con el efecto de la carga viral inicial, la carga viral preparto, el tipo de parto, el trimestre de captación y el antecedente de control prenatal.
Se determinó también su relación con el tiempo entre diagnóstico y parto y con el tiempo entre la primera carga viral registrada y el parto.

El análisis bivariado en las gestantes con seguimiento completo hasta 6 meses después del parto incluyó la relación entre el tratamiento implementado y el bajo peso al nacer, la adaptación neonatal afectada (Apgar $<6$ al nacimiento) y edad de gestación en el momento del parto.

Para las variables exploradas se realizó el análisis estratificado teniendo en cuenta el efecto de cada tratamiento sobre la "posible" asociación encontrada.

\section{Consideraciones éticas}

El proyecto aquí descrito es una intervención en salud pública orientada a la reducción y eventual eliminación de la transmisión maternoinfantil del VIH en Colombia; no se trata de un estudio experimental que pretenda reconocer el efecto de uno u otro tratamiento antirretroviral en la prevención de la transmisión vertical del VIH. La información recolectada rutinariamente para la monitorización y evaluación de los componentes del Proyecto fue utilizada como insumo para su presentación en forma agrupada y para el análisis de la situación a nivel nacional y regional. La información se mantiene en absoluta confidencialidad para cada gestante identificada. El Proyecto siguió las recomendaciones del Comité de Ética de la Unión Europea.

Todas las mujeres beneficiarias del proyecto recibieron asesoría y consejería sobre infección por VIH y sida y fueron informadas sobre su derecho a realizarse la prueba diagnóstica; las mujeres que decidieron voluntariamente practicarse la prueba diligenciaron y firmaron el formato de consentimiento informado (60). En caso de confirmación del diagnóstico, o en caso de recibir un resultado indeterminado por Western blot, y después de un nuevo proceso de asesoría, las mujeres podían aceptar o no el protocolo de atención ofrecido por el proyecto.

\section{Resultados}

El proyecto se implementó en 757 municipios (68\% del total) de 31 departamentos y sus 
actividades se llevaron a cabo en 1.062 instituciones de salud. En 121 municipios se detectaron casos de infección en mujeres gestantes.

\section{Porcentajes de seropositividad y aproximación a las prevalencias}

Entre abril de 2003 y marzo de 2005 se realizaron 200.853 pruebas de $\mathrm{VIH}$ a mujeres gestantes sin repetirlas durante la gestación. La aceptación de la prueba, reportada por 22 departamentos con base en un registro de 39.000 gestantes atendidas, fue de 97\%; 377 gestantes fueron diagnosticadas con infección por VIH (0,19\%; IC 95\%:0,169 a 0,208\%). De estas 377 mujeres, se completó el seguimiento a 285 ; las 92 restantes no habían completado los seis meses de seguimiento posparto al momento de este informe. Estas 285 mujeres recibieron algún tipo de esquema de prevención de la transmisión madre hijo.

En la figura 1 se muestra la tendencia en el número de pruebas realizadas y su posible relación con algunos hitos del proyecto, como el inicio de una campaña de televisión pautada entre octubre de 2003 y junio de 2004 por periodos no consecutivos de dos o tres meses, el convenio con 6 entidades administradoras de régimen subsidiado (febrero de 2004), la primera reunión de monitorización y la evaluación nacional con los coordinadores departamentales (abril de 2004), el inicio de una campaña de radio de 4 meses (junio a septiembre de 2004) y el ingreso de Bogotá, D.C., al proyecto (octubre de 2004); se presenta también el número de departamentos incluidos en el proyecto.

Los departamentos con mayor número de pruebas practicadas fueron: Valle del Cauca (26.754 pruebas, 13,3\%), Antioquia (22.978; 11,4\%), Atlántico (17.289; 8,6\%), Nariño (11.826; 5,9\%), Norte de Santander (11.557; 5,8\%) y Risaralda $(10.178 ; 5,1 \%)$. No se encontró correlación entre el número de pruebas realizadas y el número de gestantes infectadas con VIH. El coeficiente de correlación $\left(\mathrm{r}^{2}\right)$ fue de $25,12 \%$.

Las prevalencias registradas durante los semestres de julio a diciembre de 2003 y 2004 se presentan en el cuadro 3.

Las mayores prevalencias en el semestre de julio a diciembre de 2003 entre los departamentos con más de 500 muestras procesadas, se registraron en los departamentos de Quindío $(0,67 \%)$, La Guajira $(0,63 \%)$, Santander $(0,46 \%)$ y Córdoba $(0,37 \%)$. En el semestre de julio a diciembre de 2004, las prevalencias mayores se registraron en Quindío (0,65\%), Córdoba (0,64\%), Meta (0,44\%),

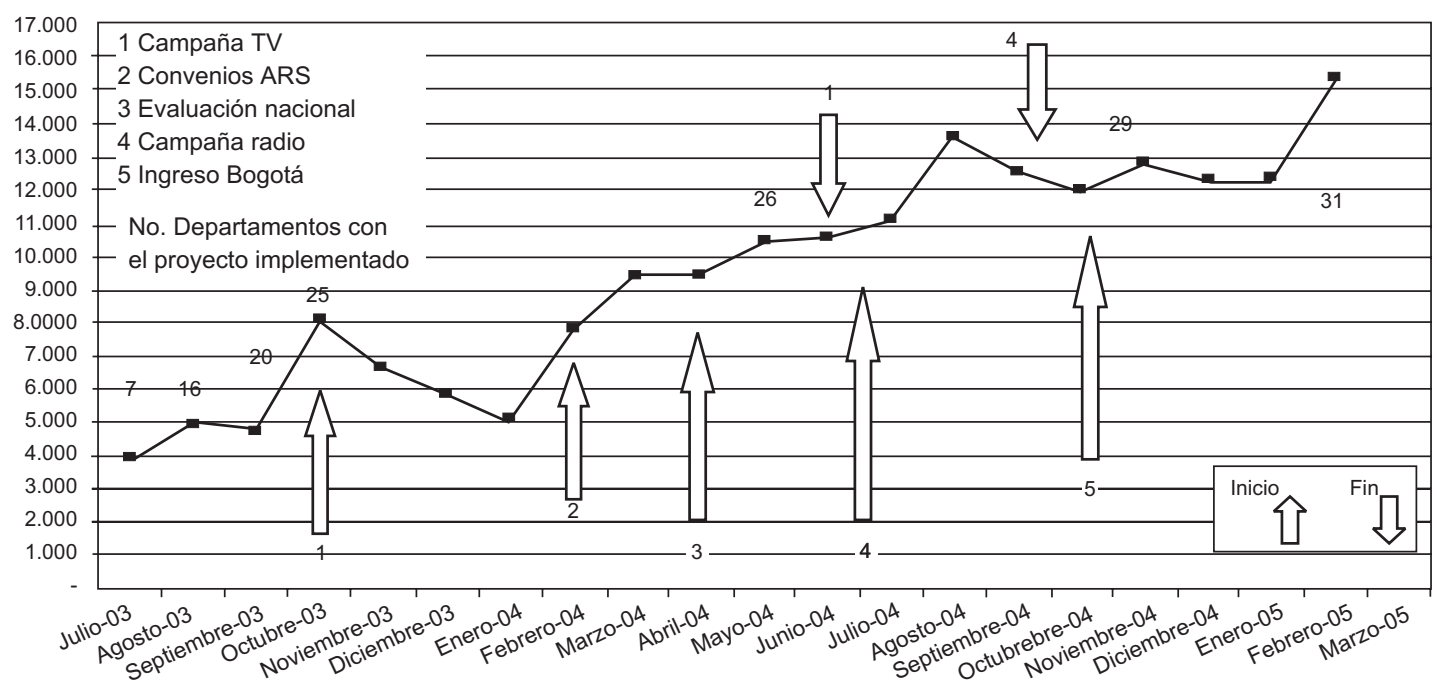

Figura 1. Pruebas de ELISA por mes en gestantes e intervención. 
Bolívar (0,37\%) y Sucre (0,32\%). A nivel nacional, la prevalencia fue de $0,19 \%$ en los dos semestres analizados (cuadro 3 ).

\section{Caracterización de las mujeres gestantes diagnosticadas}

La media de edad de las 377 gestantes en el momento de la captación fue de 24 años (DE: 5 años). Diecisiete por ciento era menor de 20 años al momento de la captación; $72 \%$ tenía unión estable, $27 \%$ era soltera; $90 \%$, amas de casa, y $4 \%$, trabajadoras sexuales.
A $11 \%$ se le realizó el diagnóstico durante el primer trimestre de embarazo y a $29 \%$ después de la semana 32. El 94,2\% tenía antecedente de control prenatal. El $84 \%$ tuvo su parto por cesárea.

La mediana del periodo comprendido entre el diagnostico confirmatorio (WB) y la evaluación de la carga viral fue de 21 días; $25 \%$ inferior a 9 días y $25 \%$ superior a 43 días; $10 \%$ tardó más de 77 días. La mediana entre la fecha del diagnóstico confirmatorio y la atención del parto fue de 78 días ( $p$ 25: 26 días y $p$ 75:146).

Cuadro 3. Prevalencias por departamento de VIH en gestantes. Semestre julio-diciembre 2003, julio-diciembre 2004.

\begin{tabular}{|c|c|c|c|c|c|c|c|c|}
\hline \multirow[b]{3}{*}{ Ente territorial } & \multicolumn{4}{|c|}{ Julio-diciembre 2003} & \multicolumn{4}{|c|}{ Julio-diciembre 2004} \\
\hline & & & LS & 니 & & & LS & 니 \\
\hline & $\mathbf{n}$ & $\%$ & IC95\% & IC95\% & $\mathbf{n}$ & $\%$ & IC95\% & IC95\% \\
\hline Amazonas & 32 & 0,00 & 0,00 & 0,00 & 234 & 0,00 & 0,00 & 0,00 \\
\hline Antioquia & 3.050 & 0,07 & $-0,02$ & 0,16 & 8.803 & 0,11 & 0,04 & 0,18 \\
\hline Atlántico & 3.276 & 0,21 & 0,05 & 0,37 & 7.091 & 0,08 & 0,01 & 0,15 \\
\hline Bogotá & & & & & 3.449 & 0,23 & 0,07 & 0,39 \\
\hline Bolívar & 1.200 & 0,17 & $-0,06$ & 0,40 & 2.458 & 0,37 & 0,13 & 0,61 \\
\hline Boyacá & 119 & 0,00 & 0,00 & 0,00 & 2.183 & 0,05 & $-0,04$ & 0,14 \\
\hline Caldas & 1.158 & 0,35 & 0,01 & 0,69 & 1.178 & 0,17 & $-0,07$ & 0,41 \\
\hline Caquetá & & 632 & 0,00 & 0,00 & 0,00 & & & \\
\hline Casanare & 404 & 0,00 & 0,00 & 0,00 & 1.766 & 0,00 & 0,00 & 0,00 \\
\hline Cauca & & & & & 2.190 & 0,00 & 0,00 & 0,00 \\
\hline Cesar & 688 & 0,00 & 0,00 & 0,00 & 871 & 0,11 & $-0,11$ & 0,33 \\
\hline Chocó & 132 & 0,00 & 0,00 & 0,00 & 195 & 0,00 & 0,00 & 0,00 \\
\hline Córdoba & 1.358 & 0,37 & 0,05 & 0,69 & 1.732 & 0,64 & 0,26 & 1,02 \\
\hline Cundinamarca & 1.426 & 0,00 & 0,00 & 0,00 & 2.737 & 0,18 & 0,02 & 0,34 \\
\hline La Guajira & 630 & 0,63 & 0,01 & 1,25 & 1.819 & 0,11 & $-0,04$ & 0,26 \\
\hline Guaviare & & & & & 14 & 0,00 & 0,00 & 0,00 \\
\hline Huila & 70 & 1,43 & $-1,35$ & 4,21 & 4.037 & 0,02 & $-0,02$ & 0,06 \\
\hline Magdalena & 300 & 1,00 & $-0,13$ & 2,13 & 2.455 & 0,20 & 0,02 & 0,38 \\
\hline Meta & 2.050 & 0,10 & $-0,04$ & 0,24 & 1.604 & 0,44 & 0,12 & 0,76 \\
\hline Nariño & 1.323 & 0,00 & 0,00 & 0,00 & 4.904 & 0,06 & $-0,01$ & 0,13 \\
\hline Norte de Santand & 2.169 & 0,18 & 0,00 & 0,36 & 4.000 & 0,23 & 0,08 & 0,38 \\
\hline Quindío & 743 & 0,67 & 0,08 & 1,26 & 1.392 & 0,65 & 0,23 & 1,07 \\
\hline Risaralda & 3.481 & 0,17 & 0,03 & 0,31 & 2.510 & 0,20 & 0,03 & 0,37 \\
\hline San Andrés & 253 & 0,00 & 0,00 & 0,00 & & & & \\
\hline Santander & 652 & 0,46 & $-0,06$ & 0,98 & 1.821 & 0,16 & $-0,02$ & 0,34 \\
\hline Sucre & 808 & 0,25 & $-0,09$ & 0,59 & 2.496 & 0,32 & 0,10 & 0,54 \\
\hline Tolima & 1.488 & 0,13 & $-0,05$ & 0,31 & 2.218 & 0,27 & 0,05 & 0,49 \\
\hline Valle & 5.482 & 0,16 & 0,05 & 0,27 & 8.854 & 0,29 & 0,18 & 0,40 \\
\hline Vichada & & & & & 254 & 0,00 & 0,00 & 0,00 \\
\hline Total & 32.292 & 0,19 & 0,14 & 0,24 & 73.897 & 0,19 & 0,16 & 0,22 \\
\hline
\end{tabular}

LS: límite superior; LI: límite inferior 
Al comparar por regiones, la captación tardía (después de la semana 36) fue mayor en la región Caribe, como lo fue el antecedente de ausencia de control prenatal, la frecuencia de parto vaginal y el número de gestantes con período menor de 90 días entre el diagnóstico confirmatorio y la atención del parto (cuadro 4).

En las mediciones realizadas en los dos procesos de evaluación efectuados en abril de 2004 y marzo de 2005, se encontraron diferencias significativas entre las mujeres beneficiarias del proyecto en cuanto a la edad de gestación al momento de la captación, el antecedente de acceso a control prenatal y la proporción de mujeres con ocupación como ama de casa (cuadro 5).

De las 285 madres a quienes se completó el seguimiento, $72(25 \%)$ fueron afiliadas al sistema de salud después de la captación. De estas 285 mujeres, $115(40,4 \%)$ continuaron recibiendo terapia antirretroviral y $21(7,3 \%)$ se mantuvieron en seguimiento clínico sin requerir tratamiento después de terminar los beneficios del proyecto; las 149 mujeres restantes no continuaron con la terapia antirretroviral ni ingresaron a un programa de atención. El 47,2\% de aquellas que fueron afiliadas al sistema de salud $(n=72)$ y $38,2 \%$ de las no afiliadas $(n=213)$ continuó recibiendo tratamiento antirretroviral después del parto (valor de $p=0,17$ ).

\section{Factores relacionados con la transmisión madre hijo}

El seguimiento clínico hasta los seis meses después del parto se completó en 285 mujeres; de estas 285 gestantes nacieron 12 niños infectados con $\mathrm{VIH}$ (4,21\%; IC95\%: 2,19 a 7,23\%). Si se excluyen las 35 mujeres que fueron captadas en el puerperio inmediato y que no recibieron profilaxis intraparto, se registraron 9 casos en niños, para una probabilidad de transmisión de 3,6\% (IC95\%:1,46 a 5,8\%).

Con excepción de las 80 gestantes que fueron captadas al final de su embarazo y que recibieron sólo profilaxis intraparto, se confirmó la infección por VIH de 3 niños (1,78\%, IC95\%: 0,37 a $5,13 \%)$. Un niño falleció por sida a los 42 días de nacido.

La probabilidad de transmisión en menores de 20 años fue de $6,7 \%(n=45)$, en el grupo de 20 a 29 años fue de $4,95 \%$ ( $n=182)$ y en mayores de 29 años, de $0 \%(n=43)$. La probabilidad de transmisión vertical fue mayor $(28,6 \%)$ en el grupo de

Cuadro 4. Diferencias en la atención de la gestante infectada con VIH por regiones.

\begin{tabular}{|c|c|c|c|c|c|c|}
\hline \multirow[t]{2}{*}{ Región } & \multirow[t]{2}{*}{$\mathbf{N}$} & \multicolumn{2}{|c|}{$\begin{array}{c}\text { Semana } \\
\text { a la captación } \\
\text { en } \%\end{array}$} & \multirow[t]{2}{*}{$\begin{array}{c}\text { Ausencia de } \\
\text { control prenatal } \\
\text { en } \%\end{array}$} & \multirow[t]{2}{*}{$\begin{array}{l}\text { Parto } \\
\text { vaginal } \\
\text { en } \%\end{array}$} & \multirow[t]{2}{*}{$\begin{array}{c}\text { Periodo } \\
\text { WB-parto } \\
<90 \text { días en \% }\end{array}$} \\
\hline & & $<16$ & $>37$ & & & \\
\hline Caribe & 84 & 4,80 & 23,80 & 13,10 & 25,00 & 50,40 \\
\hline Pacífico & 55 & 7,30 & 5,50 & 5,50 & 7,30 & 35,70 \\
\hline Andina & 128 & 9,40 & 10,90 & 4,70 & 14,80 & 44,40 \\
\hline Orinoquia-Amazonia & 18 & 11,10 & 22,20 & 0,00 & 16,70 & 50 \\
\hline
\end{tabular}

Cuadro 5. Diferencias entre dos mediciones de variables claves en gestantes infectadas con VIH, abril de 2004-marzo de 2005.

\begin{tabular}{lrrrrr}
\hline Variable & $\mathbf{2}$ Abr-04 & & Mar-05 & Valor de $\boldsymbol{p}$ \\
\hline Edad entre 15 y 19 años & $\mathbf{n}$ & \% & $\mathbf{n}$ & \% & \\
Ocupación hogar & 101 & 21 & 341 & 17 & 0,38390 \\
Captación primer trimestre & 88 & 45 & 344 & 88 & 0,00000 \\
Captación después de la semana 36 & 142 & 6 & 344 & 11 & 0,11024 \\
Parto por cesárea & 142 & 21 & 344 & 13 & 0,02557 \\
Antecedente de control prenatal & 77 & 79 & 286 & 84 & 0,33162 \\
\hline
\end{tabular}


gestantes que fueron captadas en el posparto inmediato (cuadro 6).

Se encontraron diferencias significativas $(p=0,0445)$ con respecto a una mayor reducción de la transmisión entre quienes tenían antecedente de control prenatal (9/262) comparada con las que no habían tenido control (3/20), y entre las gestantes con carga viral menor de 10.000 copias $/ \mathrm{mm}^{3}(0 / 107)$ con respecto a aquellas con carga viral mayor de 10.000 copias $/ \mathrm{mm}^{3}$ (7/92), con un valor de $p$ de 0,0040 .

\section{Efecto de los esquemas de tratamiento en la transmisión madre hijo}

Según el esquema utilizado, la probabilidad de transmisión estuvo entre $0,0 \%$ y $3,0 \%$ con la aplicación del protocolo durante el embarazo y entre $5,7 \%$ y $20,0 \%$ únicamente con la profilaxis intraparto, sin diferencias estadísticamente significativas entre los tratamientos (cuadro 7).

La probabilidad de transmisión con cesárea fue de $4,4 \%(n=225)$ y con parto vaginal de $4,3 \%$ $(n=45)$, sin diferencia estadísticamente significativa $(p=0,75)$. Entre las mujeres que recibieron algún esquema de profilaxis antirretroviral pre-parto $(n=223)$, hubo transmisión del VIH en $4 \%$ de los casos cuando el parto fue atendido por cesárea y en $0 \%$ cuando el parto fue vaginal $(n=24)$, sin que se registraran diferencias estadísticas; en una gestante no se obtuvo información sobre la vía del parto. No se encontraron diferencias en la probabilidad de transmisión relacionadas con el tratamiento utilizado ajustado por tipo de parto.

No se encontraron diferencias estadísticamente significativas en la probabilidad de transmisión entre aquellas que recibieron un tratamiento suministrado por más de 3 meses $(4 / 126)$ y quienes lo recibieron por menos de 3 meses (8/ $155)$, con un valor de $p$ de 0,398 .

\section{Monitorización de posibles efectos del tratamiento en la salud de las mujeres gestantes}

Durante las consultas de control y seguimiento, $3,9 \%$ de las gestantes reporto náusea persistente, $2,0 \%$ mareo y $1,3 \%$ diarrea relacionada con el consumo de zidovudina más lamivudina. Una gestante presentó alergia cutánea durante 24 horas con el uso de nevirapina, que cedió con el uso de antihistamínicos. Una gestante desarrolló hepatitis

Cuadro 6. Edad de la gestación en el momento de la captación y transmisión madre hijo de VIH.

\begin{tabular}{lccccc}
\hline Momento de captación & No gestantes & Niños VIH(+) & \% positividad & OR & Valor de $\boldsymbol{p}$ \\
\hline$<15$ semanas & 22 & 0 & 0,00 & 0,051 \\
15 a 28 semanas & 114 & 2 & 1,80 & 16,29 & 0,016 \\
29 a 37 semanas & 101 & 4 & 4,10 & 7,21 & 0,047 \\
> 37 semanas & 41 & 4 & 10,80 & 2,93 & 0,206 \\
Postparto & 7 & 2 & 28,60 & 1 & 0 \\
\hline
\end{tabular}

Cuadro 7. Probabilidad de transmisión VIH madre a hijo y protocolo antirretroviral.

\begin{tabular}{|c|c|c|c|c|c|}
\hline \multirow{2}{*}{$\begin{array}{l}\text { Esquema de tratamiento (semanas) }^{\star} \\
\text { ZDV }^{\star *} \text { (sem 14-32) ZDV+3TC (sem 32-38) }\end{array}$} & \multirow{2}{*}{$\begin{array}{l}\mathbf{N} \\
52\end{array}$} & \multirow{2}{*}{$\begin{array}{c}\text { Niños VIH (+) } \\
2\end{array}$} & \multirow{2}{*}{$\begin{array}{c}\text { \% Niños VIH (+) } \\
3,9\end{array}$} & \multicolumn{2}{|c|}{$\begin{array}{c}\text { Intervalo de } \\
\text { confianza } 95 \%\end{array}$} \\
\hline & & & & 0,47 & 13,21 \\
\hline ZDV+3TC (sem 32-38) & 75 & 0 & 0,0 & 0,00 & 0,00 \\
\hline ZDV+3TC+NFV (sem 14-38) & 33 & 1 & 3,0 & 0,08 & 15,75 \\
\hline ZDV+3TC+NVP (sem 14-38) & 8 & 0 & 0,0 & 0,00 & 0,00 \\
\hline Sólo ZDV intraparto & 70 & 4 & 5,7 & 1,58 & 14,02 \\
\hline ZDV+NVP intraparto & 10 & 2 & 20,0 & 2,52 & 55,61 \\
\hline Total & 248 & 9 & 3,6 & 1,46 & 5,80 \\
\hline
\end{tabular}

* La profilaxis intraparto incluyó ZDV I.V. y la profilaxis al recién nacido expuesto fue con ZDV+3TC durante 6 semanas.

** Ver cuadro 1 
previa al tratamiento, que contraindicó el uso de nevirapina.

\section{Monitorización de posibles efectos del tratamiento en el neonato}

El $10,5 \%$ de los neonatos fue pretérmino (menos de 37 semanas de gestación en el momento del parto), $4,3 \%$ no tuvo adaptación neonatal inmediata (Apgar menor de 7/10 en los primeros 5 minutos) y $16,7 \%$ tuvo bajo peso al nacer (peso menor de $2.500 \mathrm{~g}$ ), sin diferencias estadísticamente significativas por esquema de tratamiento seleccionado (cuadro 8).

En la región Caribe $(n=84), 3,6 \%$ de los partos fueron prematuros, $13,1 \%$ de los niños expuestos tuvieron bajo peso al nacer y 6,0\%, Apgar menor de 7. En la región Pacífico $(n=55)$ estas proporciones fueron de $9,1 \%, 12,7 \%$ y $1,8 \%$, respectivamente, y en la región Andina $(n=128)$, $8,6 \%, 21,9 \%$ y $6,3 \%$, respectivamente.

\section{Discusión}

La iniciativa nacional de reducción de la transmisión madre hijo es actualmente la acción más eficaz de la respuesta nacional ante la epidemia de $\mathrm{VIH} /$ sida, pues ha reducido la posibilidad de transmisión perinatal de $40 \%$ a $3,6 \%$; con la aplicación completa del protocolo, que consta de tratamiento antirretroviral, parto por cesárea, profilaxis intraparto y al recién nacido expuesto, y sustitución de la leche materna, esta probabilidad se reduce a $1,78 \%$, porcentaje que se encuentra en el nivel de $1 \%$ a $2 \%$ estimado con la aplicación óptima de la estrategia (1621,64 ), pero que es menor que el 16\% (IC95:13 a $20 \%$ ) registrado por Brasil con diferentes estrategias de prevención (65). Este nivel está relacionado estrechamente con la captación tardía de la gestante o la ausencia de antecedente de control prenatal (66), pues se ha demostrado que una captación oportuna significaría la eliminación de la transmisión perinatal (67).

La transmisión perinatal reportada es consistente con los hallazgos de otros estudios que reportaron mayor probabilidad de infección neonatal cuando la carga viral inicial es superior a 10.000 copias/ $\mathrm{mm}^{3}$, probabilidad que aumenta cuanto más tarde se inicia el tratamiento durante el embarazo (6869). El suministro del tratamiento $A R V$ combinado con $Z D V+3 T C+N F V$ o $Z D V+3 T C+N V P$ debe contribuir a que este subgrupo obtenga una reducción mayor (18).

No se encontraron diferencias en la probabilidad de transmisión entre las gestantes a quienes se realizó parto vaginal y aquéllas a quienes se les realizó cesárea electiva, pero este hallazgo se relacionó con una muestra de 45 partos vaginales y 225 cesáreas, lo que afecta ostensiblemente la comparación. El protocolo de atención (60) indica la realización de la cesárea de acuerdo con los hallazgos de la literatura (49-53), y los partos

Cuadro 8. Monitorización del carácter prematuro, depresión neurológica y bajo peso al nacer como posibles efectos de los medicamentos antirretrovirales in utero y tratamiento antirretroviral utilizado.

\begin{tabular}{|c|c|c|c|c|c|c|}
\hline \multirow[t]{2}{*}{ Esquemas* } & \multicolumn{2}{|c|}{ Carácter prematuro } & \multicolumn{2}{|c|}{$\begin{array}{c}\text { Depresión } \\
\text { neurológica } \\
\text { (Apgar<7) }\end{array}$} & \multicolumn{2}{|c|}{ Bajo peso al nacer } \\
\hline & $\mathbf{n}$ & $\%$ & $\mathbf{n}$ & $\%$ & $\mathbf{n}$ & $\%$ \\
\hline$Z^{2 D V * *}$ (sem 14-32) ZDV+3TC (sem 32-38) & 53 & 13,2 & 45 & 8,9 & 49 & 14,3 \\
\hline ZDV + 3TC (sem 32-38) & 79 & 6,3 & 77 & 3,9 & 78 & 19,2 \\
\hline ZDV + 3TC + NFV (sem 14-38) & 33 & 12,1 & 32 & 0 & 32 & 15,6 \\
\hline ZDV + 3TC + NVP (sem 14-38) & 8 & 12,5 & 8 & 0 & 8 & 25,0 \\
\hline Sólo ZDV intraparto & 67 & 11,9 & 65 & 4,6 & 66 & 15,2 \\
\hline ZDV + NVP intraparto & 8 & 12,5 & 8 & 0 & 8 & 12,5 \\
\hline Total & 248 & 10,5 & 235 & 4,3 & 276 & 16,7 \\
\hline Referencia bibliográfica & \multicolumn{2}{|c|}{$(61)$} & \multicolumn{2}{|c|}{$(62)$} & \multicolumn{2}{|c|}{ (63) } \\
\hline
\end{tabular}

*La profilaxis intraparto incluyó ZDV, IV, y la profilaxis al recién nacido expuesto fue con ZDV + 3TC durante 6 semanas.

** Ver cuadro 1. 
vaginales se debieron a dificultades en la remisión de las gestantes en el nivel regional.

Todos los esquemas de tratamiento utilizados redujeron la tasa de transmisión madre-hijo, sin diferencias estadísticas debidas al esquema utilizado; el progresivo incremento de la captación temprana y del inicio oportuno del tratamiento durante el embarazo resultó en la reducción de la probabilidad de transmisión. La aplicación de la profilaxis intraparto se constituyó en un pilar del protocolo, dada la posibilidad de controlar entre $55 \%$ y $65 \%$ de los casos, reduciendo el riesgo a la mitad (70-74). Tener cohortes limitadas en cada tratamiento dificulta establecer las verdaderas diferencias entre los tratamientos utilizados y, en general, entre las diferentes variables analizadas.

El parto prematuro, el bajo peso al nacer o el daño neurológico del recién nacido, que han sido reportados en la literatura científica como posibles efectos del tratamiento antirretroviral durante la gestación (56,61-63), no se relacionaron con ninguno de los tratamientos antirretrovirales utilizados, encontrándose un valor de p menor de 0,05; sin embargo, es necesario continuar con el seguimiento clínico de estos infantes y niños para comprobar la seguridad de la profilaxis antirretroviral o detectar posibles efectos de la exposición in utero a estos medicamentos $(56,72)$.

La población de mujeres adolescentes embarazadas aportó $17 \%$ de los casos diagnosticados, evidenciando la necesidad de fortalecer las estrategias y acciones que refuercen la información, educación y comunicación en salud sexual y reproductiva en este grupo poblacional en el marco de las políticas de salud sexual y reproductiva. La probabilidad de transmisión fue mayor en el grupo de adolescentes, contrario a lo encontrado en otros estudios realizados en Latinoamérica, en los cuales la transmisión fue mayor en mujeres mayores de 20 años (66); sin embargo, no se presentaron diferencias estadísticas de la probabilidad de transmisión por grupo de edad, en contraste con las diferencias reportadas en cohortes europeas (73).

Durante el periodo analizado se hicieron inicialmente 4.000 pruebas mensuales, alcanzándose la cifra de 15.000 pruebas durante los últimos meses. Este aumento significativo del número de pruebas se relacionó con la progresiva inclusión de nuevos departamentos, municipios e instituciones de salud, con los procesos de mercadeo social a través de los medios de comunicación, con el evento de evaluación nacional al año de ejecución de actividades, y con los procesos de capacitación y asistencia técnica que se llevaron a cabo en forma continua durante todo el proyecto. Los momentos de búsqueda "activa" con mayor número de pruebas, no se relacionaron con un aumento en los casos detectados, posiblemente porque estas acciones se llevaron a cabo en los municipios con mayor cobertura y calidad del control prenatal, y no en municipios donde la prevalencia de infección puede ser mayor.

La prevalencia de período encontrada en los dos semestres analizados fue de $0,19 \%$, muy inferior al $0,64 \%$ de prevalencia estimada en la población general, de acuerdo con los resultados del último estudio centinela efectuado en 2003 (74), y al $0,7 \%$ de las estimaciones efectuadas en 2004 por Onusida y el Ministerio de la Protección Social (75).

Una explicación parcial de la diferencia entre la prevalencia nacional estimada y las prevalencias encontradas podría ser el hecho de que gran parte de la población de mujeres gestantes vulnerables se encuentran en el régimen subsidiado, de acuerdo con los criterios de focalización para el acceso al aseguramiento en salud, mientras que el proyecto sólo abordó a las gestantes no aseguradas, lo que contribuye a tener una visión de lo que ocurre sólo en esta subpoblación, y no en toda la población de mujeres vulnerables; es de anotarse que en la población subsidiada se ha estimado una doble prevalencia de VIH comparada con la de otros grupos de afiliación (74).

De acuerdo con las prevalencias obtenidas, las regiones más afectadas continúan siendo la Costa Atlántica, los Santanderes, el Eje Cafetero y el Valle del Cauca. Este hallazgo concuerda con lo reportado previamente en relación con un mayor número de casos en mujeres y en población heterosexual en estas regiones $(6,26)$. A esto se 
suma, particularmente en la región Caribe, un menor acceso al control prenatal, una captación más tardía, barreras para el acceso integral a la prevención de la transmisión madre-hijo (parto vaginal) y un menor tiempo de terapia antirretroviral antes del parto (menor de 90 días). Es necesario hacer un mayor énfasis en el fortalecimiento de los programas de atención prenatal y de prevención de $\mathrm{VIH} /$ sida en esta región del país.

Los resultados confirman las mayores prevalencias e incidencia de infección en mujeres de la región Caribe y sugieren que en el departamento del Quindío, donde tradicionalmente se ha reportado un predominio de la transmisión entre hombres que tienen sexo con hombres, se presenta actualmente un cambio significativo del patrón predominante de transmisión sexual (6-8).

La atención integral posparto, incluida la continuidad del tratamiento antirretroviral una vez se deja de recibir por parte del proyecto, sólo alcanza a $48 \%$ de las mujeres inicialmente atendidas. El $52 \%$ restante no recibe tratamiento antirretroviral por diferentes razones. A pesar de las acciones de abogacía realizadas a nivel nacional y regional, no fue posible afiliar a 213 mujeres al sistema de aseguramiento en salud. Entre las 37 que fueron afiliadas y que no continuaron el tratamiento, ello se debió, entre otras razones, al no suministro de la terapia ARV por parte de la entidad aseguradora, y a la no realización de pruebas como la de carga viral, necesaria para la definición del tratamiento de elección y su seguimiento. Esta situación refleja las barreras aún existentes para la atención de las personas que viven con $\mathrm{VIH} /$ sida, incluso cuando están afiliadas al sistema de salud (26).

El proyecto madre-hijo ha permitido renovar el esquema de desarrollo, fortalecimiento y sostenimiento de un programa de salud pública con un esquema de coordinación nacional, coordinaciones departamentales y equipos locales de atención. Este esquema permitió que progresivamente se constituyera una red de diagnóstico, atención integral y seguimiento clínico, con cobertura en 31 departamentos, 4 distritos, 757 municipios y 1.062 instituciones de salud para el control de la transmisión de $\mathrm{VIH}$ madre hijo. Esto podría indicar la conveniencia de retomar e implementar nuevamente mecanismos de coordinación nacional en algunos programas prioritarios en salud pública.

Durante el tiempo transcurrido del proyecto, algunos departamentos o municipios han fortalecido, paralelamente, sus actividades de mejoramiento del control prenatal, de abordaje de la pareja, de seguimiento clínico y psicosocial al binomio madre positiva-hijo, de tamizaje de otros eventos de interés en salud pública (sífilis, hepatitis $B$ ), de mercadeo social del proyecto en medios de comunicación locales, y de aseguramiento del tratamiento posparto para la gestante. Además, el proyecto ha logrado un mayor acceso a los servicios de salud, a los profesionales entrenados, a los servicios de asesoría y consejería, a la red de diagnóstico y al suministro del tratamiento, lo que unido a lo que desarrollan los departamentos y municipios, contribuye a tener soporte para el sostenimiento de la estrategia y a cumplir con los componentes óptimos para la prevención $(66,75,76)$. Después de la primera reunión de evaluación nacional se evidenció un mejoramiento en la oportunidad del diagnóstico, en el suministro de medicamentos, en el funcionamiento de la red de laboratorios, y en el seguimiento del binomio madre-hijo. Estas actividades contribuyeron a una optimización de los procesos, y de manera definitiva a la disminución de la transmisión de VIH madre-hijo.

La prevención de la transmisión madre-hijo contribuye a disminuir el impacto del sida en nuestra población a corto y largo plazo (76-78). No sólo es una intervención eficaz para disminuir la incidencia de infecciones pediátricas sino para promover el fortalecimiento de cambios de actitud y de conducta de las mujeres en sus propias relaciones sexuales y frente a la reducción del estigma que puede significar "hacerse la prueba" (79). Es necesario continuar y fortalecer las acciones orientadas a la participación de las entidades aseguradoras en el sostenimiento de esta iniciativa. Las actividades de promoción y prevención no son aún una prioridad en todas las entidades promotoras de salud y en las administradoras del régimen subsidiado, pero recientemente se ha avanzado en los procesos 
de concertación y consenso entre los subsectores de salud pública y de aseguramiento en salud, así como en la formulación de normas legislativas orientadas al mejoramiento de la atención integral de las personas afectadas por el VIH o el sida (80).

Aunque la respuesta nacional a la epidemia del $\mathrm{VIH} /$ sida es un compromiso de todos los sectores sociales, el logro de algunos objetivos específicos depende del compromiso y la respuesta gubernamentales en todos sus niveles. Uno de estos objetivos, que es un desafío nacional actual, es lograr la reducción de la transmisión maternoinfantil del $\mathrm{VIH}$, y asegurar el sostenimiento de las acciones de este proyecto una vez concluya la cooperación internacional, para lo cual es necesario que las entidades del sistema de salud asuman su responsabilidad. EI sostenimiento de esta iniciativa como política de salud pública será fundamental para mantener la prevalencia de la infección por debajo de $1 \%$ a nivel nacional $(75,78)$. En el corto plazo es prioritario asegurar la continuidad del tratamiento antirretroviral a todas las madres que lo requieran, permitiéndoles aumentar su supervivencia y mejorar su calidad de vida, y reduciendo consecuentemente la mortalidad en mujeres y la orfandad a causa del sida $(20,47,71)$.

\section{Nota informativa}

El Proyecto Nacional de Reducción de la Transmisión Madre Hijo de VIH, dirigido y coordinado por la alianza ONUSIDA/INS/ FEREDSALUD, con financiación de la Comisión Europea, se desarrolla en Colombia desde 2003. Este proyecto facilita los componentes e insumos básicos de asesoría y diagnóstico en $\mathrm{VIH}$ a mujeres embarazadas y ofrece atención integral a la madre infectada con VIH y a su hijo expuesto.

Información sobre el proyecto: línea de atención gratuita 018000110073, PBX 57-1-6164676, correo electrónico proyectomadrehijo@yahoo.com y en URL:http//www.onusida.org.co.

\section{Agradecimientos}

Los autores reconocen y agradecen el trabajo de todos los profesionales vinculados al proyecto en la coordinación nacional, los departamentos, los municipios y las instituciones públicas de salud participantes.

\section{Conflicto de intereses}

El contenido del presente artículo es responsabilidad exclusiva de sus autores y en ningún caso debe considerarse como la opinión de la Comisión Europea.

\section{Financiación}

El proyecto fue financiado por la Comisión Europea mediante Contrato COL/AIDCO/2001/ 0473.

\section{Referencias}

1. Steinbrook R. The AIDS epidemics in 2004. N Eng J Med 2004;351:115-7.

2. Onusida. El género y el VIH/Sida. Actualización Técnica. Ginebra: Onusida; 2000.

3. OPS/OMS. La mujer y la infección por $\mathrm{VIH} /$ sida: estrategias de prevención y atención. Washington: OPS/ OMS; 1999.

4. Interagency Gender Working Group Task Force Report. How to integrate gender into HIV/AIDS programs: using lessons learned from USAID and partner organizations. Washington, D.C.: USAID; 2004.

5. Onusida. Informe sobre la epidemia mundial de sida 2004. Ginebra: Onusida; 2004.

6. Garcia-Bernal R, Klaskala W, Castro J, Zhang G, Baum M. HIV/AIDS epidemic in Colombia: regional differences in epidemic trends. AIDS 1997;11:1297-8.

7. Onusida, Unicef, OMS. Colombia: epidemiological fact sheets on HIV/AIDS and sexually transmitted infections; 2004 Update. Ginebra: Onusida; 2004.

8. Prieto F. Veinte años del VIH en Colombia, 1983-2003. Datos de la vigilancia epidemiológica. Inf Quinc Epidemiol Nac 2003;8:355-66.

9. Mock PA, Shaffer N, Bhadrakom C, Siriwasin W, Chotpitayasunondh T, Chearskul $S$ et al. Maternal viral load and timing of mother-to-child HIV transmission, Bangkok, Thailand. AIDS 1999;13:407-14.

10. Connor EM, Sperling RS, Gelber R, Kiselev P, Scott G, O'Sullivan MJ et al. Reduction of maternal-infant transmission of human immunodeficiency virus type 1 with zidovudine treatment. N Eng J Med 1994;331:117380.

11. Centers for Diseases Control and Prevention. Recommendations of the Public Health Service on use of zidovudine to reduce perinatal transmission of human immunodeficiency virus. MMWR Recomm Rep 1994; 43:1-20. 
12. Wiktor SZ, Ekpini E, Karon JM, Nkengasong J, Maurice C, Severin ST et al. Short-course oral zidovudine for prevention of mother-to-child transmission of HIV-1 in Abidjan, Cóte d'Ivoire: a randomised trial. Lancet 1999;353:781-5.

13. Shaffer N, Chuachoowong R, Mock PA, Bhadrakom C, Siriwasin W, Young NL et al. Short-course zidovudine for perinatal HIV-1 transmission in Bangkok, Thailand: a randomised controlled trial. Lancet 1999;353:773-80.

14. Lallemant M, Jourdain G, Le Coeur S, Kim S, Koetsawang S, Cemeau AM et al. A trial of shortened zidovudine regimens to prevent mother-to-child transmission of human immunodeficiency virus type 1 . Perinatal HIV Prevention Trial (Thailand) Investigators. N Engl J Med 2000;343:982-91.

15. Petra Study Team. Efficacy of three short-course regimens of zidovudine and lamivudine in preventing early and late transmission of HIV-1 from mother to child in Tanzania, South Africa, and Uganda (Petra study): a randomized, double-blind, placebo-controlled trial. Lancet 2002;359:1178-86.

16. Mandelbrot L, Landreau-Mascaro A, Rekacewicz C, Berrebi A, Benifla JL, Burgard M et al. Lamivudinezidovudine combination for prevention of maternal-infant transmission of HIV-1. JAMA 2001;285:2083-93.

17. Eshleman SH, Guay LA, Fleming T, Mwatha A, Mracna M, Becker-Pergola $\mathbf{G}$ et al. Survival of Ugandan infants with subtype $A$ and D HIV-1 infection (HIVNET 012). J Acquir Immune Defic Syndr 2002;31: 327-30.

18. Cooper ER, Charurat M, Mofenson L, Hanson IC, Pitt J, Diaz C et al. Combination antiretroviral strategies for the treatment of pregnant HIV-1 infected women and prevention of perinatal HIV-1 transmission. J Acquir Immune Defic Syndr 2002;29:484-94.

19. Watts DH. Management of human immunodeficiency virus infection in pregnancy. N Engl J Med 2002;346: 1879-91.

20. Organización Mundial de la Salud. Expansión del tratamiento antirretroviral en entornos con recursos limitados: directrices para un enfoque de salud pública. Ginebra: OMS; 2003.

21. Newell ML. Prevención de la transmisión maternoinfantil del VIH: retos para la década entrante. Boletín de la Organización Mundial de la Salud 2002;670-6.

22. Franco A. Seguridad social y salud en Colombia: estado de la reforma. Rev Salud Pública 2000;2:1-16.

23. Jaramillo I. Evaluación de la descentralización de la salud y la reforma de la Seguridad Social en Colombia. Gac Sanit 2002;16:48-53.

24. Departamento Administrativo de Planeación. Metas y estrategias de Colombia para el logro de los objetivos de desarrollo del milenio-2015. Documento de CONPES Social 2005; 91. [Consultado 10 de junio de 2005] Disponible en URL: http://www.dnp.gov.co.

25. Ministerio de Salud. Resolución 00412 de 2000. Por la cual se establecen las actividades, procedimientos e intervenciones de demanda inducida y obligatorio cumplimiento y se adoptan las normas técnicas y guías de atención para el desarrollo de las acciones de protección específica y detección temprana y la atención de enfermedades de interés en salud pública. Norma de detección temprana de las alteraciones del embarazo. Bogotá DC: Ministerio de Salud; 2000.

26. Onusida, Ministerio de Salud. Infección por VIH y sida en Colombia: aspectos fundamentales, respuesta nacional y situación actual. Un balance histórico hacia el nuevo siglo. Bogotá: Onusida; 1999.

27. Profamilia. Salud sexual y reproductiva en Colombia: resultados Encuesta Nacional de Demografía y Salud 2000. Bogotá, D.C.: Measure/DHS; 2000.

28. Centers for Diseases Control and Prevention. Update: Universal precautions for prevention of transmission of human immunodeficiency virus, hepatitis $B$ virus, and other blood borne pathogens in health care settings. MMWR Morb Mortal Wkly Rep 1988;37:37787.

29. World Health Organization. Guidelines for the safe transport of infectious substances and diagnostic specimens. WHO/EMC/97.3. Geneva: WHO; 1997.

30. Arkin CF, Bessman JD, Calam RR, Ernst DJ, Parish GT, Szamosi DI et al. Procedures for the collection of diagnostic blood specimens by venipuncture; approved standard. Fifth edition. Wayne: NCCLS document H3A5; 2003.

31. Bencomo JF, Santín M, Torres R, Fdez Yero JL, Silva C, Pozo L et al. La red nacional de laboratorios SUMA: soporte tecnológico en el pesquisaje seroepidemiológico del VIH-sida en Cuba. Jornal Brasileiro de Doenças Sexualmente Transmissíveis 2003;15:5-11.

32. Centers for Diseases Control and Prevention. Interpretation and use of the western blot assay for serodiagnosis of human immunodeficiency virus type 1 infections. Morbid Mortal Weekly Report 1989;38:1-7.

33. Hausler WJ Jr. Report of the Third Consensus Conference on HIV testing sponsored by the Association of State and Territorial Public Health Laboratory Directors. Infect Control Hosp Epidemiol 1988;9:345-9.

34. Gwinn M, Redus MA, Granade TC, Hannon WH, George JR. HIV-1 serologic test results for one million newborn dried-blood specimens: assay performance and implications for screening. J Acquir Immune Defic Syndr 1992;5:505-12.

35. Celum CL, Coombs RW, Lafferty W, Inui TS, Louie PH, Gates CA et al. Indeterminate human immunodefi- 
ciency virus type 1 western blots: seroconversion risk, specificity of supplemental tests, and an algorithm for evaluation. J Infect Dis 1991;164:656-64.

36. Jackson JB, MacDonald KL, Cadwell J, Sullivan C, Kline WE, Hanson M et al. Absence of HIV infection in blood donors with indeterminate western blot tests for antibody to HIV-1. N Eng J Med 1990;322:217-22.

37. Boucher FD, Modlin JF, Weller S, Ruff A, Mirochnick $\mathbf{M}$, Pelton S et al. Phase I evaluation of zidovudine administered to infants exposed at birth to the human immunodeficiency virus. J Pediatr 1993;122:137-44.

38. Capparelli EV, Mirochnick M, Wayne M, Danker WM, Blanchard S, Mofenson L et al. Pharmacokinetics and tolerance of zidovudine in preterm infants. J Pediatr 2003;142:47-52.

39. Dorenbaum A, Cunningham $\mathbf{C K}$, Gelber RD, Culnane M, Mofenson L, Brito P et al. Two-dose intrapartum/newborn nevirapine and standard antiretroviral therapy to reduce perinatal HIV transmission: a randomized trial. JAMA 2002;288:18998.

40. Guay LA, Musoke P, Fleming T, Bagenda D, Allen $\mathbf{M}$, Nakabiito $\mathbf{C}$ et al. Intrapartum and neonatal singledose nevirapine compared with zidovudine for prevention of mother-to-child transmission of HIV in Kampala Uganda: HIVNET 012 randomised trial. Lancet 1999;354:795-802.

41. Bucceri AM, Somigliana E, Matrone R, Ferraris G, Rossi G, Grossi E et al. Combination antiretroviral therapy in $100 \mathrm{HIV}-1$-infected pregnant women. Hum Reprod 2002;17:436-41.

42. McGowan JP, Crane M, Wiznia AA, Blum S. Combination antiretroviral therapy in human immunodeficiency virus-infected pregnant women. Obstet Gynecol 1999;94:641-6.

43. World Health Organization. Antiretroviral drugs for treating pregnant women and preventing HIV infection in infants. Guidelines on care, treatment and support for women living with HIV/AIDS and their children in resource-constrained settings. Ginebra: WHO; 2004.

44. Lallemant M, Jourdain G, Le Coeur S, Mary JY, NgoGiang-Huong N, Koetsawang $S$ et al. Single-dose perinatal nevirapine plus standard zidovudine to prevent mother-to-child transmission of HIV-1 in Thailand. N Engl J Med 2004;351:217-28.

45. Rouet F, Montcho C, Rouzioux C, Leroy V, Msellati P, Kottan JB et al. Early diagnosis of pediatric HIV-1 Infection among African breast-fed children using quantitative plasma HIV RNA assay. AIDS 2001;15; 1849-56.

46. American Academy of Pediatrics. Committee on Pediatric AIDS. Evaluation and medical treatment of the HIV-exposed infant. Pediatrics 1997;99:909-17.
47. Centers for Diseases Control and Prevention. Guidelines for national human immunodeficiency virus case surveillance, including monitoring for human immunodeficiency virus infection and acquired immunodeficiency syndrome. MMWR Recomm Rep 1999;48:1-31.

48. Rose NR, De Macario EC, Fahey JL, Friedman H, Penn GM. Manual of clinical immunology. 4th ed. Washington, D.C.: American Society of Microbiology; 2002.

49. Dunn DT, Newell ML, Mayaux MJ, Kind C, Hutto C, Goedert JJ et al. Mode of delivery and vertical transmission of HIV-1: a review of prospective studies. J Acquir Immune Defic Syndr 1994;7:1064-6.

50. Kuhn L, Bobat R, Coutsoudis A, Moodley D, Coovadia HM, Tsai WY et al. Cesarean deliveries and maternal-infant HIV transmission: results from a prospective study in South Africa. J Acquir Immune Defic Syndr Hum Retrovirol 1996;11:478-83.

51. The International Perinatal HIV Group. The mode of delivery and the risk of vertical transmission of human immunodeficiency virus type 1: a meta-analysis of 15 prospective cohort studies. N Eng J Med 1999; 340:97787.

52. The European Mode of Delivery Collaboration. Elective caesarean-section versus vaginal delivery in prevention of vertical HIV-1 transmission: a randomized clinical trial. Lancet 1999;353:1035-9.

53. Landers DV, Duarte G. Mode of delivery and the risk of vertical transmission of HIV-1. N Engl J Med 1999; 341:205-7.

54. Bulterys M Fowler MG, Van Rompay KK, Kourtis AP. Prevention of mother-to-child transmission of HIV1 through breast feeding: past, present, and future. $\mathrm{J}$ Infect Dis 2004;189:2149-53.

55. Coutsoudis A, Dabis F, Fawzi W, Gaillard P, Haverkamp G, Harris DR et al. Late postnatal transmission of HIV-1 in breast-fed children: an individual patient data meta-analysis. J Infect Dis 2004; 189:215466.

56. Public Health Service Task Force. Recommendations for use of antiretroviral drugs in pregnant HIV-1-infected women for maternal health and interventions to reduce perinatal HIV-1 transmission in the United States. 2005. Washington, D.C.: NIH; 2005.

57. República de Colombia. Ley 76 de 1985. Por la cual se crea la región de planificación de la Costa Atlántica, se dictan otras disposiciones sobre planificación regional y se otorgan facultades extraordinarias al Presidente de la República.

58. Dunn DT, Brandt CD, Krivine A, Cassol SA, Roques P, Borkowsky W et al. The sensitivity of HIV-1 DNA polymerase chain reaction in the neonatal period and the relative contributions of intra-uterine and intrapartum transmission. AIDS 1995;9:F7-11. 
59. Owens DK, Holodniy M, McDonald TW, Scout J, Sonnad S. A meta-analytic evaluation of the polymerase chain reaction for the diagnosis of HIV infection in infants. JAMA 1996;275:1342-8.

60. Arenas C, Prieto F, García R, Rincón J, Caicedo S. Proyecto Nacional de Reducción de la Transmisión Madre Hijo del VIH: manual de procedimientos. $2^{\mathrm{a}}$ edición. Bogotá: Unión Europea; 2005.

61. Lorenzi P, Spicher VM, Laubereau B, Hirschel B, Kind C, Rudin C et al. Antiretroviral therapies in pregnancy: maternal, fetal and neonatal effects. AIDS 1998;12:F241-7.

62. Blanche S, Tardieu M, Rustin P, Slama A, Barret B, Firtion $G$ et al. Persistent mitochondrial dysfunction and perinatal exposure to antiretroviral nucleoside analogues. Lancet 1999;354:1084-9.

63. Culnane M, Fowler M, Lee SS, McSherry G, Brady M, O'Donnell $\mathrm{K}$ et al. Lack of long-term effects of in utero exposure to zidovudine among uninfected children born to HIV-infected women. Pediatric AIDS Clinical Trials Group Protocol 219/076 Teams. JAMA 1999;281:151-7.

64. Wade NA, Birkhead GS, Warren BL, Charbonneaux TT, French PT, Wang $L$ et al. Abbreviated regimens transmission of the human immunodeficiency virus. $\mathrm{N}$ Engl J Med 1998;339:1409-14.

65. Tess BH, Rodrigues LC, Newell ML, Dunn D, Lago TD. Breastfeeding, genetic, obstetric and other risk factors associated with mother-to-child transmission of HIV-1 in Sao Paulo State, Brazil. The São Paulo Collaborative Study for Vertical Transmission of HIV-1. AIDS 1998;12:513-20.

66. Nishimoto TMI, Neto JE, Rozman MA. Transmissão materno - infantil do vírus da imunodeficiência humana: avaliação de medidas de controle no município de Santos. Rev Assoc Med Bras 2005;51:54-60.

67. Sambamoorthi U, Akincigil A, McSpiritt E, Crystal S. Zidovudine use during pregnancy among HIV-infected women on Medicaid. J Acquir Immune Defic Syndr 2002; 30:429-39.

68. Sperling R, Shapiro D, Coombs R, Todd J, Herman S, McSherry G et al. Maternal viral load, zidovudine treatment, and the risk of transmission of human immunodeficiency virus type 1 from mother to infant. $\mathrm{N}$ Engl J Med 1996;335:1621-9.

69. Garcia PM, Kalish LA, Pitt J, Minkoff H, Quinn TC, Burchett SK et al. Maternal levels of plasma human immunodeficiency virus type 1 RNA and the risk of perinatal transmission. The Women and Infants Transmission Study Group. N Engl J Med 1999; 341:394402.

70. Newell ML. Mechanism and timing of mother-to-child transmission of HIV-1. AIDS 1998;12:831-37.

71. World Health Organization. Nuevas orientaciones para prevenir la transmisión maternofilial del virus de la inmunodeficiencia humana. Rev Panam Salud Pública 2004;16:289-94.

72. European Collaborative Study. Exposure to antiretroviral therapy in utero or early life: the health of uninfected children born to HIV-infected women. J Acquir Immune Defic Syndr 2003;32:380-7.

73. European Collaborative Study. Vertical transmission of HIV-1: maternal immune status and obstetrics factors. AIDS 1996;10:1675-81.

74. Prieto F, Osorio A, De Neira M, Grupo de Vigilancia Centinela de VIH. Prevalencia de VIH en población general de Colombia 2003: VI Estudio Nacional Centinela de VIH 2003-2004. Primera Fase. Informe Quincenal Epidemiológico Nacional 2004;9:362-75.

75. Onusida, Ministerio de la Protección Social. Capítulo 8: Objetivo 6. Combatir el VIH/SIDA y otras enfermedades. En: DNP. Informe sobre metas del milenio 2004. Bogotá, D.C.: DNP, 2004.

76. Rutenberg N, Kalibala S, Baek C, Rosen J. Programmed recommendations for the prevention of mother-to-child transmission of HIV: A practical guide for managers. New York: Unicef HIV/AIDS Working Paper; 2003.

77. Stover J, Walker N, Garnett GP, Salomon JA, Stanecki KA, Ghys PD et al. Can we reverse the HIV/ AIDS pandemic with an expanded response? Lancet 2002;360:73-7.

78. Ministerio de la Protección Social - Onusida. Plan Intersectorial de Respuesta ante el VIH/sida. Colombia 2004-2007. Onusida, Bogotá DC: Onusida-Ministerio de la Protección Social (Colombia); 2004.

79. International Center for Research on Women - ICRW. Community involvement \& the prevention of mother-tochild transmission of HIV/AIDS. Washington, 2002: ICRW. [Consultado 15 de junio de 2005]. Disponible en URL: http://www.icrw.org

80. República de Colombia. Ley 972 de 2005. Por la cual se adoptan normas para mejorar la atención por parte del Estado colombiano de la población que padece de enfermedades ruinosas o catastróficas, especialmente el VIH/SIDA. 